\title{
Análise da concordância entre as informações reportadas pelas mães e dos cartões de vacina das crianças no Brasil (2013 e 2015)
}

\section{Analysis of the agreement between information on child vaccination reported by mothers and that on the children's vaccination cards in Brazil (2013-2015)}

\author{
Mônica Viegas Andrade (D), Kenya Noronha' (D), Clareci Silva Cardoso² (D), Cláudia Di Lorenzo Oliveira² (D), \\ Júlia Almeida Calazans ${ }^{1}$ [D, Michelle Nepomuceno Souza ${ }^{1}$ (D) \\ ${ }^{1}$ Faculdade de Ciências Econômicas - Centro de Desenvolvimento e Planejamento Regional (Cedeplar), Universidade Federal de \\ Minas Gerais (UFMG) - Belo Horizonte (MG), Brasil \\ ${ }^{2}$ Departamento de Medicina, Universidade Federal de São João del-Rei - São João del-Rei (MG), Brasil
}

Como citar: Andrade MV, Noronha K, Cardoso CS, Oliveira CL, Calazans JA, Souza MN. Análise da concordância entre as informações reportadas pelas mães e dos cartões de vacina das crianças no Brasil (2013 e 2015). Cad Saúde Colet, 2021;29(esp.):40-50. https://doi.org/10.1590/1414-462X202199010302

\section{Resumo}

Introdução: Este trabalho discute a possibilidade de utilização de informações sobre a vacinação infantil reportada pelas mães em inquéritos domiciliares para a construção de indicadores de cobertura vacinal no Brasil.

Objetivo: Avaliar o potencial das informações declaradas pelas mães sobre a imunização das crianças em inquéritos domiciliares como uma fonte para o cálculo do indicador de cobertura vacinal.

Método: Analisaram-se os indicadores de confiabilidade (precisão) e validade (concordância) entre as informações disponíveis nos cartões de vacina das crianças menores de 2 anos e as informações reportadas pelas mães em pesquisas domiciliares realizadas nos anos de 2013 e 2015 no município de Santo Antônio do Monte, Minas Gerais.

Resultados: O principal resultado mostra que, em um contexto de alta cobertura, as mães tendiam a informar sobre a vacinação de seus filhos de forma aleatória, ou seja, informações reportadas pelas mães apresentavam baixa validade.

Conclusão: Embora a coleta de informações dos cartões de vacina das crianças seja um procedimento mais custoso, essa é a forma mais adequada e confiável de se mensurar a cobertura vacinal no contexto brasileiro.

Palavras-chave: vacinas; estudos de validação; autorreportado.

\section{Abstract}

Background: This study discusses the possibility of using information on child vaccination reported by mothers through household surveys to construct indicators of immunization coverage in Brazil.

Objective: Evaluate the potential of information reported by mothers on the immunization of children in household surveys as a source to calculate a vaccination coverage indicator.

Method: The indicators of reliability (accuracy) and validity (concordance) between the information available on the vaccination cards of children under two years of age and that reported by mothers in

Fonte de Financiamento: Organização Pan-Americana da Saúde (OPAS), Conselho Nacional de Secretários Municipais de Saúde (CONASS), FUNDAÇÃO DE APOIO À PESQUISA DO ESTADO DE MINAS GERAIS (FAPEMIG)/PROGRAMA DE PESQUISA PARA O SUS (PPSUS)/EDITAL 14/2013 PROCESSO APQ0355913.

Conflito de Interesses: nada a declarar.

Recebido em: Ago. 04, 2019. Aprovado em: Dez. 26, 2019
Este é um artigo publicado em acesso aberto (Open Access) sob a licença Creative Commons Attribution, que permite uso, distribuição e reprodução em qualquer meio, sem restrições desde que o trabalho original seja corretamente citado. 
two household surveys conducted in 2013 and 2015 in the municipality of Santo Antônio do Monte, state of Minas Gerais, Brazil.

Results: The main result shows that, in a context of high coverage, the mothers tended to inform randomly about the vaccination of their children, that is, the information reported by mothers presented low validity. Conclusion: Although collecting information from children's vaccination cards is a more costly procedure, it is the most adequate and reliable way to measure vaccination coverage in the Brazilian context.

Keywords: vaccine; validation studies; self-report.

\section{INTRODUCÃO}

Desde a criação do Plano Nacional de Imunização em 1973, a imunização infantil se destaca por ser uma das políticas de saúde mais bem-sucedidas no Brasil, alcançando uma cobertura próxima da universalidade para as vacinas preconizadas pelo Ministério da Saúde para crianças menores de 5 anos de idade ${ }^{1,2}$. Para que o monitoramento das metas de vacinação seja feito de forma eficiente, são necessários bons indicadores de cobertura vacinal.

No Brasil, o indicador oficial de cobertura vacinal é obtido por meio da razão entre o número de doses aplicadas de determinada vacina e a estimativa da população na idade específica da vacinação ${ }^{3,4,5}$ Por sua vez, o número de doses aplicadas é calculado com base nos boletins mensais emitidos pelos postos de vacinação. Esse indicador de cobertura vacinal é intuitivo, direto, de simples interpretação e pode ser calculado para diversas unidades geográficas e períodos no tempo, fazendo com que ele seja amplamente utilizado na avaliação da cobertura. Contudo, muitas vezes esse indicador pode fornecer estimativas imprecisas, visto que ele está passível de erros tanto no registro das doses aplicadas quanto nas estimativas populacionais ${ }^{5,6,7}$ No cálculo das doses aplicadas, são contabilizadas todas as doses efetivamente recebidas, independentemente da idade em que foram aplicadas. Desse modo, crianças que tomam doses fora da idade adequada são contabilizadas no numerador de cobertura vacinal. O denominador também é passível de erro, uma vez que as estimativas populacionais, principalmente para crianças de 0 a 2 anos, também apresentam erros em decorrência da subenumeração dos registros de nascimentos no país ${ }^{8}$. Como resultado, o indicador de cobertura vacinal, na maior parte das vezes, pode estar superestimado, especialmente em municípios menores. Por exemplo, em Minas Gerais, em 2015, a cobertura vacinal calculada pelo Ministério da Saúde para as vacinas BCG, hepatite B, rotavírus, pneumocócica, meningocócica e tríplice viral estava acima de $100 \%{ }^{4}$.

Uma forma alternativa de aferir a cobertura vacinal é por meio de pesquisas domiciliares. Nesse caso, duas informações podem ser investigadas: (1) a declaração das mães ou responsáveis sobre a vacinação das crianças; e (2) a verificação do cartão de vacina. A vantagem do uso de pesquisas domiciliares é a possibilidade de avaliar a cobertura vacinal considerando atributos socioeconômicos e demográficos das famílias das crianças. Do ponto de vista de política pública, é fundamental entender o alcance dos programas de imunização e identificar os grupos populacionais mais vulneráveis. O indicador oficial do Ministério da Saúde só permite análises em que o menor nível de desagregação é o município.

A verificação direta do cartão de vacina já tem sido realizada para o Brasil| ${ }^{6,8,9,10,11}$. Em 2007, um estudo mais amplo incluindo todas as capitais foi realizado para aferir a real cobertura vacinal em crianças menores de 18 meses de idade pelo grupo Vaccine Coverage Survey $2007^{12}$. Segundo essa pesquisa, a cobertura para as crianças da amostra era de $83 \%$, sendo a cobertura maior nos grupos com menor renda familiar, evidenciando uma desigualdade favorável na cobertura vacinal entre os grupos socioeconômicos mais baixos.

Nas pesquisas domiciliares, a forma mais fácil de aferir a cobertura vacinal é por intermédio da informação reportada pelas mães. Pesquisas de âmbito nacional, como a Pesquisa Nacional de Saúde (PNS/IBGE) ${ }^{13}$, realizada em 2013, investigam a imunização das crianças menores de 1 ano a partir de informações declaradas pelas mães.

O objetivo deste estudo foi, portanto, avaliar o potencial das informações declaradas pelas mães sobre a imunização das crianças em inquéritos domiciliares como uma fonte para o cálculo do indicador de cobertura vacinal. Para tanto, a declaração das mães sobre a imunização de seus filhos foi comparada com o registro dos cartões de vacina dessas crianças coletados em 
uma pesquisa de campo realizada no município de Santo Antônio do Monte (Minas Gerais, Brasil) nos anos de 2013 e 2015.

Diversos estudos buscam validar as informações sobre cobertura vacinal reportadas em pesquisas domiciliares a partir de registros administrativos e médicos ${ }^{14-28}$. A maioria desses artigos avalia as informações atinentes à cobertura das vacinas contra gripe (influenza) e pneumonia nos Estados Unidos, Reino Unido, Espanha, França, Itália e Austrália.

De forma geral, esses estudos mostram que a cobertura vacinal, calculada a partir das informações declaradas, está muito próxima aos registros oficiais para a vacina contra influenza, sendo que a concordância entre as duas fontes de informação varia entre $95 \% \%^{15,18,28}$ e 98\% $\%^{17,24,27}$. Já para a vacina contra pneumonia, a concordância varia entre $64 \% \%^{28}$ e $90 \%{ }^{20}$. Lu et al. ${ }^{25} \mathrm{e}$ Boakye et al. ${ }^{26}$ analisaram os dados da National Immunization Survey-Teen (NIS-Teen) para a cobertura vacinal de adolescentes americanos de 13 a 17 anos para as vacinas contra gripe (influenza) e HPV, respectivamente. Nos dois estudos, entre os adolescentes com registro clínico, $86 \%$ dos pais afirmaram que seu filho havia tomado a vacina.

Brown et al. ${ }^{16}$ compararam dados relacionados à vacina contra influenza para 3.072 crianças americanas, no estudo de New Vaccine Surveillance Network. Essa pesquisa questionou os pais das crianças sobre o recebimento de vacina contra influenza e conferiu a resposta com o profissional provedor da vacina. Os resultados encontrados no estudo mostraram que os pais tendiam a responder corretamente sobre o status vacinal das crianças ( $92 \%$ de sensibilidade e $82 \%$ de especificidade), porém a concordância entre as respostas diminuía com o aumento do tempo após o recebimento da vacina.

Uma série de estudos vem ressaltando também a importância das características sociodemográficas e econômicas como fatores determinantes da concordância entre a informação reportada e os registros oficiais ${ }^{15,21,22,29}$. As mulheres tendem a responder sobre suas vacinas de forma mais similar aos registros oficiais do que os homens. Por outro lado, a concordância de crianças e idosos tende a ser menor que a concordância de jovens adultos. Martin et al. ${ }^{21}$ também mostraram que indivíduos com maior acesso aos serviços básicos de saúde têm maiores chances de responder sobre seu status de vacinação de maneira similar aos registros oficiais. Rolnick et al. ${ }^{22}$ ressaltam que a concordância entre as informações declaradas e os registros administrativos e clínicos varia expressivamente entre as vacinas. A vacina contra hepatite $A$ tem as menores taxas de concordância, enquanto as vacinas contra tétano, HPV e gripe apresentam elevadas taxas de concordância.

Ainda que a literatura a respeito da validação das informações declaradas sobre cobertura vacinal seja vasta, esse campo de estudo ainda não está esgotado. O presente artigo se coloca como uma importante contribuição, uma vez que busca validar as informações de cobertura vacinal para um grupo até então inédito na literatura: as crianças de até 2 anos de idade. No Brasil, a maioria das vacinas é ministrada na primeira infância, de modo que as informações reportadas pelas mães em pesquisas domiciliares podem se configurar como um importante mecanismo de monitoramento da cobertura vacinal no país.

\section{MÉTODO}

\section{Fonte de dados}

Este estudo utilizou as informações fornecidas por um inquérito domiciliar realizado em dois recortes transversais independentes no município de Santo Antônio do Monte, em Minas Gerais, no âmbito da Pesquisa de Avaliação do Laboratório de Inovações no Atenção às Condições Crônicas (LIACC) na Atenção Primária à Saúde ${ }^{30}$. Essa pesquisa avaliou as mudanças em diversos indicadores de saúde antes, no decorrer e depois da intervenção do LIACC para indivíduos com hipertensão, diabetes, gestantes e crianças menores de 2 anos.

As datas de realização das entrevistas eram referentes aos períodos antes e depois do processo de intervenção do LIACC no município. As entrevistas respondidas em 2013 diziam respeito às crianças nascidas entre janeiro de 2011 e dezembro de 2012, enquanto as entrevistas respondidas em 2015 se referiam às crianças nascidas entre janeiro e dezembro de 2014. 
O tamanho amostral foi definido a partir do número médio anual de nascimentos ocorridos no município de Santo Antônio do Monte, registrados no Sistema de Informação sobre Nascidos Vivos (SINASC). A amostra final foi representativa da população de crianças menores de 2 anos do município, sendo investigadas 185 crianças em 2013 e 155 crianças em 2015.

Primeiramente, perguntou-se às mães se a criança havia tomado pelo menos uma dose de cada vacina analisada: BCG-ID, hepatite B, antipólio, tetravalente, rotavírus, pneumocócica, meningocócica, tríplice viral e febre amarela. Em seguida, as mães responderam se a criança tinha cartão de vacina e se ele estava presente no momento da entrevista. Esses cartões foram fotografados pelos entrevistadores com o consentimento das mães, e a elaboração do banco de dados com tais informações teve dupla checagem para a garantia da qualidade informacional. Optou-se por trabalhar com pelo menos uma das doses para que fosse possível realizar a comparação com as informações reportadas pelas mães.

Os indicadores foram construídos apenas para as crianças que tinham a idade completa preconizada pelo calendário vacinal do Ministério da Saúde, com uma janela de tempo de dois meses. Essa janela é necessária, pois, muitas vezes, a criança não tomou a vacina na idade exata por estar com algum problema de saúde ou por indisponibilidade/descontinuidade do próprio sistema ${ }^{31}$ Não há na literatura um acordo sobre o tempo válido de espera para a próxima dose da vacina ${ }^{6}$, por isso tal estratégia foi adotada sem um parâmetro predefinido.

O calendário vacinal do Ministério da Saúde sempre passa por alterações no que tange ao número de doses e à idade de cada uma das vacinas. Este trabalho utilizou o calendário vigente até o ano de 2015, uma vez que as crianças analisadas foram imunizadas a partir das normas do calendário antigo. Ressalta-se que, durante o ano de 2012, a vacina tetravalente foi substituída pela pentavalente, e em muitos cartões de vacina analisados o carimbo ou a anotação que validava a aplicação da vacina vinha com uma observação de que a criança não tinha tomado a tetravalente, mas sim a pentavalente. Nesses casos, o trabalho considerou a criança imune pela tetravalente.

Esta pesquisa foi avaliada e aprovada pelo Comitê de Ética em Pesquisa da UFSJ/Campus Centro-Oeste Dona Lindu, sob o Parecer no 369.942, no ano de 2013. Os dados individuais coletados se tornaram anônimos e não apareceram em nenhum relatório ou publicação, sendo resguardado o direito ao sigilo. Após a pesquisa, os dados foram arquivados e não foram utilizados para outro fim, de acordo com os princípios do art. $6^{\circ}$ da Lei Geral de Proteção de Dados $^{32}$, em especial o da segurança e transparência, e o art. $7^{\circ}$ da referida lei, quanto ao tratamento dos dados. Informações completas sobre a pesquisa estão disponíveis no relatório técnico entregue à Organização Pan-Americana de Saúde em novembro de 2016.

\section{Indicadores de confiabilidade e validade das informações autodeclaradas}

Os registros dos cartões de vacina foram considerados como o grupo de referência para a avaliação da qualidade das informações autodeclaradas das mães. As consistências entre as duas fontes de dados foram analisadas a partir de seis indicadores amplamente utilizados em estudos epidemiológicos ${ }^{33}$ :

1. Sensibilidade: proporção de crianças que foram vacinadas segundo o relato materno entre aquelas vacinadas com base nos cartões de vacina.

2. Especificidade: proporção de crianças que não foram vacinadas conforme o relato materno entre aquelas não vacinadas com base nos cartões de vacina.

3. Valor preditivo positivo: proporção de crianças que foram vacinadas com base nos cartões de vacina entre aquelas vacinadas de acordo com o relato das mães.

4. Valor preditivo negativo: proporção de crianças que não foram vacinadas com base nos cartões de vacina entre aquelas não vacinadas conforme o relato das mães.

5. Taxa de concordância geral: proporção de concordância entre as respostas das mães e os registros nos cartões.

6. Índice Kappa: taxa de concordância geral, ponderada pela concordância esperada. Esse índice, usualmente, varia entre 0 e 1, de tal forma que, quanto maior for seu valor, maior é 
a concordância entre as duas fontes de informação. Contudo, em algumas circunstâncias, é possível observar um índice Kappa negativo, quando a concordância observada é menor que a concordância esperada. Valores negativos baixos (até $-0,1$ ) são usualmente interpretados como não concordância ${ }^{34}$.

Parte da consonância verificada pela taxa de concordância geral pode ser aleatória, e não em decorrência da concordância entre as duas fontes de informação. Assim, o índice Kappa é estatisticamente superior à taxa de concordância geral, uma vez que, ao ponderar a taxa de concordância geral pela taxa de concordância esperada, é possível obter a concordância líquida, para além daquela que seria esperada ao acaso.

\section{RESULTADOSE DISCUSSÃO}

Realizaram-se entrevistas com 340 mães de crianças de até 2 anos de idade nos anos de 2013 e 2015. A maioria dessas mães tinha entre 20 e 35 anos (76,47\%), com pelo menos o ensino fundamental completo $(59,42 \%)$ e pertencente à classe de riqueza $C(56,64 \%)$, utilizando os parâmetros do Critério Brasil da Associação Brasileira de Empresa de Pesquisa de 2014 ${ }^{35}$. Todas as mães declararam que a criança tinha cartão de vacina. Contudo, 42 crianças foram excluídas da análise, uma vez que 33 mães não deixaram os entrevistadores verem o cartão de vacina da criança, 8 mães afirmaram que a criança já teve outro cartão de vacina e 1 mãe não sabia se a criança já havia tido outro cartão. Dessa forma, a análise da cobertura vacinal considerou 298 crianças, as quais representavam $88 \%$ da amostra inicial. Não houve diferenças socioeconômicas estatisticamente significativas entre as mães das crianças da amostra inicial e o subgrupo selecionado.

A Tabela 1 apresenta as taxas de cobertura vacinal para as crianças de até 2 anos de idade no município de Santo Antônio do Monte nos anos de 2013 e 2015, considerando as informações reportadas pelas mães e os registros presentes nos cartões de vacina. Em primeiro lugar, notou-se elevada cobertura no município para as vacinas preconizadas no primeiro ano de vida, independentemente da informação utilizada. Com base nas informações dos cartões, 100\% das crianças tomaram pelo menos uma dose de BCG-ID, antipólio, pneumocócica, meningocócica e febre amarela. Para as demais, a cobertura vacinal foi de $99 \%$.

Tabela 1. Cobertura vacinal declarada pelas mães e registrada no cartão de vacina para crianças menores de 2 anos, Santo Antônio do Monte, Minas Gerais, 2013 e 2015

\begin{tabular}{|c|c|c|c|c|c|c|c|}
\hline & \multicolumn{2}{|c|}{$\begin{array}{l}\text { Cobertura } \\
\text { vacinal - mãe }\end{array}$} & \multicolumn{2}{|c|}{$\begin{array}{l}\text { Cobertura } \\
\text { vacinal - } \\
\text { cartões }\end{array}$} & \multicolumn{2}{|c|}{ Teste de média } & \multirow{2}{*}{$\begin{array}{c}\begin{array}{r}\text { Total de crianças } \\
\text { elegíveis à vacina }\end{array} \\
\mathbf{n}\end{array}$} \\
\hline & $\mathbf{n}$ & $\%$ & $\mathbf{n}$ & $\%$ & p-valor & Significância & \\
\hline BCG-ID & 283 & 98,26 & 288 & 100 & 0,025 & $* *$ & 288 \\
\hline Hepatite B & 285 & 98,28 & 288 & 99,31 & 0,254 & NS & 290 \\
\hline Antipólio & 275 & 98,57 & 279 & 100 & 0,045 & $* *$ & 279 \\
\hline Tetravalente & 261 & 93,21 & 279 & 99,64 & 0 & $* * *$ & 280 \\
\hline Rotavírus & 268 & 96,4 & 277 & 99,64 & 0,006 & $* * *$ & 278 \\
\hline Pneumocócica & 241 & 87,32 & 276 & 100 & 0 & $* * *$ & 276 \\
\hline Meningocócica & 229 & 82,37 & 278 & 100 & 0 & $* * *$ & 278 \\
\hline Tríplice viral & 150 & 97,4 & 152 & 98,7 & 0,41 & NS & 154 \\
\hline Febre amarela & 158 & 96,34 & 164 & 100 & 0,013 & $* *$ & 164 \\
\hline
\end{tabular}

Fonte: Pesquisa SAMONTE (2013 e 2015); Nota: ${ }^{* * *}$ Estatisticamente significativo a $1 \%$; ${ }^{* *}$ Estatisticamente significativo a $5 \%$;

* Estatisticamente significativo a 10\%; NS Não estatisticamente significativo 
A cobertura vacinal estimada com base nas respostas das mães foi elevada, mas foi menor do que a estimada de acordo com os registros dos cartões. As diferenças entre a resposta da mãe e a informação do cartão foram estatisticamente significativas para todas as vacinas, exceto para hepatite $B$ e tríplice viral. As maiores diferenças foram observadas para as vacinas tetravalente, pneumocócica e meningocócica (Tabela 1). Essas vacinas, como mencionado na metodologia, passaram por mudanças no calendário vacinal, o que pode levar a um maior desconhecimento delas por parte das mães.

Algumas mudanças que ocorreram no calendário vacinal preconizado pelo Ministério da Saúde podem, em alguma medida, explicar a subdeclaração pelas mães. A vacina tetravalente foi substituída no ano de 2012 pela pentavalente que protege contra difteria, tétano, coqueluche, Haemophilus influenza tipo B e hepatite B. Essa mudança pode justificar a subestimação de resposta para hepatite $B$ e tetravalente. No caso das vacinas pneumocócica e meningocócica, a subestimação pode estar associada à inclusão recente dessas duas vacinas no calendário vacinal, que passaram a ser ofertadas somente a partir de 2010. Possivelmente as mães tiveram dificuldades de identificar a imunização da criança por causa da pouca familiaridade e da baixa difusão de informações sobre essas vacinas.

A Tabela 2 apresenta os índices de sensibilidade e especificidade entre as informações declaradas pelas mães e as informações registradas nos cartões de vacina das crianças menores de 2 anos em Santo Antônio do Monte. De forma geral, entre as crianças com registro no cartão, houve um percentual expressivo de mães que declararam que a criança tomou a vacina. Para as vacinas BCG-ID, hepatite B, antipólio, tríplice viral e febre amarela, a sensibilidade foi maior que $97 \%$. Por outro lado, a proporção de mães que declararam que a criança tomou a vacinas pneumocócica e meningocócica entre aquelas com registro no cartão foi de $88 \%$ e $83 \%$ respectivamente, indicando que, para essas vacinas, houve uma menor concordância entre mães e cartões. Por outro lado, em todos os casos em que não havia registro no cartão, as mães declararam que a criança tinha tomado a vacina, ou seja, a especificidade foi igual a zero para todas as vacinas. Desse modo, observa-se uma fragilidade na resposta das mães que reportaram que a criança sempre recebeu a vacina.

Tabela 2. Sensibilidade e especificidade para a concordância entre as informações declaradas pelas mães e as informações registradas no cartão de vacina para crianças menores de 2 anos, Santo Antônio do Monte, Minas Gerais, 2013 e 2015

\begin{tabular}{|c|c|c|c|c|c|c|c|}
\hline & \multirow{2}{*}{$\begin{array}{l}\text { Crianças com } \\
\text { registro no } \\
\text { cartão }\end{array}$} & \multicolumn{2}{|c|}{ Sensibilidade } & \multirow{2}{*}{$\begin{array}{l}\text { Crianças sem } \\
\text { registro no } \\
\text { cartão }\end{array}$} & \multicolumn{2}{|c|}{ Especificidade } & \multirow{2}{*}{$\begin{array}{c}\text { Crianças } \\
\text { elegíveis à } \\
\text { vacina }\end{array}$} \\
\hline & & $\mathbf{n}$ & $\%$ & & $\mathbf{n}$ & $\%$ & \\
\hline BCG-ID & 288 & 283 & 98.26 & 0 & 0 & 0.00 & 288 \\
\hline Hepatite B & 288 & 283 & 98.26 & 2 & 0 & 0.00 & 290 \\
\hline Antipólio & 294 & 290 & 98.64 & 0 & 0 & 0.00 & 294 \\
\hline Tetravalente & 290 & 271 & 93.45 & 1 & 0 & 0.00 & 291 \\
\hline Rotavírus & 284 & 274 & 96.48 & 1 & 0 & 0.00 & 285 \\
\hline Pneumocócica & 285 & 250 & 87.72 & 0 & 0 & 0.00 & 285 \\
\hline Meningocócica & 286 & 237 & 82.87 & 0 & 0 & 0.00 & 286 \\
\hline Tríplice viral & 168 & 164 & 97.62 & 22 & 0 & 0.00 & 190 \\
\hline Febre amarela & 211 & 205 & 97.16 & 2 & 0 & 0.00 & 213 \\
\hline
\end{tabular}

Fonte: Pesquisa SAMONTE (2013 e 2015); Nota: ** Estatisticamente significativo a 1\%; ** Estatisticamente significativo a 5\%;

* Estatisticamente significativo a 10\%; NS Não estatisticamente significativo 
Assim, quando a criança não tomava uma vacina específica, a mãe tendia a afirmar que a criança a tinha tomado. Esse padrão de resposta provavelmente tenha sido influenciado pela elevada cobertura vacinal observada no município. Como a cobertura foi próxima de $100 \%$, as mães, em geral, tendiam a reportar que as crianças estavam com todas as vacinas em dia. É interessante ressaltar o caso que ocorreu com a vacina tríplice viral. Entre 2012 e 2014, segundo o relato dos profissionais de saúde de Santo Antônio, o município passou por problemas de abastecimento dessa vacina, de modo que um percentual significativo das crianças não a tomou. Mesmo assim, todas as mães afirmaram que seus filhos tomaram a vacina tríplice viral.

A Tabela 3 apresenta os valores preditivos positivos e negativos para a concordância entre as informações declaradas pelas mães e as informações nos cartões de vacina das crianças menores de 2 anos em Santo Antônio do Monte. Para todas as vacinas, com exceção da tríplice viral, constatou-se que, para praticamente todas as crianças cuja mãe havia declarado que elas tomaram a vacina, havia registro também no cartão, uma vez que o valor preditivo positivo foi maior que $99 \%$. Por outro lado, entre as crianças cuja mãe havia declarado que elas não tinham tomado a vacina, todas tinham registro no cartão, de modo que o valor preditivo negativo foi igual a zero para todas as vacinas.

Tabela 3. Valor preditivo positivo e valor preditivo negativo para a concordância entre as informações declaradas pelas mães e as informações registradas no cartão de vacina para crianças menores de 2 anos, Santo Antônio do Monte, Minas Gerais, 2013 e 2015

\begin{tabular}{|c|c|c|c|c|c|c|c|}
\hline & \multirow{2}{*}{$\begin{array}{c}\text { Afirmação a } \\
\text { partir do relato } \\
\text { materno }\end{array}$} & \multicolumn{2}{|c|}{ PPV } & \multirow{2}{*}{$\begin{array}{c}\text { Negação } \\
\text { a partir } \\
\text { do relato } \\
\text { materno }\end{array}$} & \multicolumn{2}{|c|}{ NPV } & \multirow{2}{*}{$\begin{array}{l}\text { Crianças } \\
\text { elegíveis à } \\
\text { vacina }\end{array}$} \\
\hline & & $\mathbf{n}$ & $\%$ & & $\mathbf{n}$ & $\%$ & \\
\hline BCG-ID & 283 & 283 & 100.00 & 5 & 0 & 0.00 & 288 \\
\hline Hepatite B & 285 & 283 & 99.30 & 5 & 0 & 0.00 & 290 \\
\hline Antipólio & 290 & 290 & 100.00 & 4 & 0 & 0.00 & 294 \\
\hline Tetravalente & 272 & 271 & 99.63 & 19 & 0 & 0.00 & 291 \\
\hline Rotavírus & 275 & 274 & 99.64 & 10 & 0 & 0.00 & 285 \\
\hline Pneumocócica & 250 & 250 & 100.00 & 35 & 0 & 0.00 & 285 \\
\hline Meningocócica & 237 & 237 & 100.00 & 49 & 0 & 0.00 & 286 \\
\hline Tríplice viral & 186 & 164 & 88.17 & 4 & 0 & 0.00 & 190 \\
\hline Febre amarela & 207 & 205 & 99.03 & 6 & 0 & 0.00 & 213 \\
\hline
\end{tabular}

Fonte: Pesquisa SAMONTE (2013 e 2015); Nota: ${ }^{* * *}$ Estatisticamente significativo a 1\%; ${ }^{* *}$ Estatisticamente significativo a 5\%;

* Estatisticamente significativo a 10\%; NS Não estatisticamente significativo

A Tabela 4 apresenta a taxa de concordância geral e o índice Kappa para a concordância entre as informações declaradas pelas mães e as informações nos cartões de vacina das crianças menores de 2 anos em Santo Antônio do Monte. Notou-se um alto nível de concordância para todas as vacinas, embora existisse expressiva variação entre os tipos. A maior taxa de concordância foi observada para a BCG-ID (98\%), o que era esperado, uma vez que essa vacina é tomada em geral na maternidade, e a menor foi a meningocócica (83\%).

Embora a taxa de concordância geral estivesse bastante elevada, esse indicador não foi suficiente para garantir a validade da informação das mães, uma vez que seu valor foi fortemente determinado pela concordância entre as respostas positivas das mães e os registros no cartão. Como a especificidade e o valor preditivo negativo foram iguais a zero, ao ponderar a concordância observada pela concordância esperada, foi obtido o índice Kappa próximo a zero para praticamente todas as vacinas, o que significa que a concordância percebida entre as 
Tabela 4. Taxa de concordância geral e índice Kappa para a concordância entre as informações declaradas pelas mães e as informações registradas no cartão de vacina para crianças menores de 2 anos, Santo Antônio do Monte, Minas Gerais, 2013 e 2015

\begin{tabular}{lcccc}
\hline & $\begin{array}{c}\text { Número de mães } \\
\text { e cartão em } \\
\text { concordância }\end{array}$ & $\begin{array}{c}\text { Taxa de } \\
\text { concordância } \\
\text { geral }\end{array}$ & $\begin{array}{c}\text { Índice Kappa } \\
\text { Crianças elegíveis } \\
\text { à vacina }\end{array}$ \\
\hline BCG-ID & 283 & 98.26 & 0.00 & 288 \\
\hline Hepatite B & 283 & 97.59 & -0.01 & 290 \\
\hline Antipólio & 290 & 98.64 & 0.00 & 294 \\
\hline Tetravalente & 271 & 93.13 & -0.01 & 291 \\
\hline Rotavírus & 274 & 96.14 & -0.01 & 285 \\
\hline Pneumocócica & 250 & 87.72 & 0.00 & 285 \\
\hline Meningocócica & 237 & 82.87 & 0.00 & 190 \\
\hline Tríplice viral & 164 & 86.32 & -0.04 & 213 \\
\hline Febre amarela & 205 & 96.24 & -0.01 & 286 \\
\hline
\end{tabular}

Fonte: Pesquisa SAMONTE (2013 e 2015)

respostas das mães e o registro no cartão foi aleatória. No caso específico em análise, como a cobertura vacinal era muito elevada, os dados sugerem que as mães tendiam sempre a reportar que os filhos tomaram a vacina.

O Gráfico 1 analisa a discordância entre as duas fontes de informação. No total, 194 mães reportaram todas as vacinas em concordância com as informações dos cartões e 94 crianças tiveram informação reportada em pelo menos uma vacina em discordância com as informações registradas nos cartões de vacina, sendo que a maioria das mães reportaram até três vacinas em divergência com os cartões. Ademais, as mães que não reportaram de forma correta a vacinação de seus filhos não diferiam em termos socioeconômicos das demais mães entrevistadas no que se refere à idade, classe de riqueza e escolaridade. Esse achado é importante, pois sugere que o desconhecimento da informação pelas mães não está relacionado a características específicas delas.

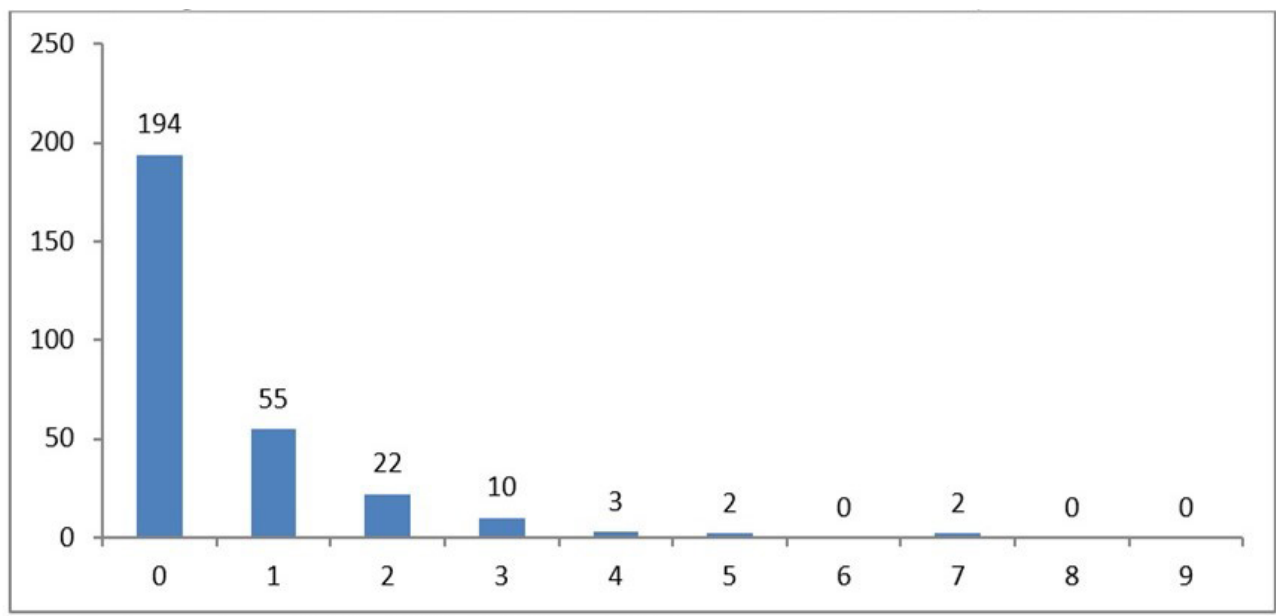

Fonte: Pesquisa SAMONTE, 2013 e 2015.

Gráfico 1. Número de discordâncias entre as informações declaradas pelas mães e as informações registradas no cartão de vacinas para cada criança menor de 02 anos - Santo Antônio do Monte, 2013 e 2015 


\section{CONSIDERAÇÕES FINAIS}

Este trabalho analisou a possibilidade de utilização de informações sobre a vacinação infantil reportadas pelas mães para a construção de indicadores de cobertura vacinal em um município brasileiro de pequeno porte. O estudo é inédito no Brasil, uma vez que são escassos os trabalhos de validação de informações domiciliares sobre a cobertura vacinal infantil.

A principal limitação do estudo é se referir a uma população específica de um município de pequeno porte no Brasil, sendo, portanto, um estudo de caso. A despeito da particularidade do município, o estudo gera novas evidências para políticas de monitoramento da cobertura vacinal no Brasil.

Os resultados mostraram que, em um contexto de alta cobertura, as mães tendiam a informar sobre a vacinação de seus filhos de forma aleatória. A evidência de Santo Antônio do Monte mostra que a informação reportada pelas mães tinha pouca validade para mensurar a cobertura vacinal. Esse contexto difere dos demais estudos que buscaram validar informações autorreportadas sobre vacinas para outros grupos populacionais. Como a cobertura vacinal era alta, as mães provavelmente tinham baixo conhecimento específico sobre cada vacina, não sendo capazes de identificar quais estavam fora do calendário adequado. Esses resultados estão em consonância com os achados de Brown et al. ${ }^{16}$, que já evidenciaram a fragilidade das informações reportadas pelas mães no que tange à vacinação das crianças.

A baixa concordância das informações das mães ficou mais evidente para a vacina tríplice viral. Segundo relato dos profissionais de saúde, entre os anos de 2012 e 2014, o município de Santo Antônio do Monte apresentou problemas de abastecimento dessa vacina. Ainda assim, todas as mães declararam que seus filhos haviam tomado essa vacina.

A não concordância entre as informações declaradas pelas mães e as informações dos cartões de vacina pode ser gerada por causa do viés de memória das mães ${ }^{29}$. Contudo, a partir dos resultados apresentados neste estudo, não se pode afirmar que a não concordância seja decorrente de um viés de memória ou de falta de informação por parte das mães. Cordeiro et al. ${ }^{36}$, ao analisarem o esquema vacinal de crianças assistidas em uma Unidade Básica de Saúde no município de Jaboatão dos Guararapes, Pernambuco, evidenciaram a falta de conhecimento das mães e ressaltaram a importância de práticas educativas na atenção primária.

O Brasil alcançou, com o Sistema Único de Saúde, elevada cobertura vacinal infantil. A poliomielite, a varíola e o sarampo foram erradicados, e a incidência de diversas outras doenças infecciosas, como febre amarela, difteria, tétano neonatal, coqueluche, meningite, caxumba e rubéola, tem sido mantida em níveis relativamente baixos. No município de Santo Antônio do Monte, assim como para a maioria dos municípios brasileiros, foi observada universalização da cobertura vacinal para as crianças de 0 a 2 anos.

Contudo, nos últimos anos, o número de famílias que decidem não vacinar seus filhos vem crescendo expressivamente em diversos países do mundo ${ }^{37,38}$. Ainda que o movimento antivacina seja pequeno no Brasil, ele vem ganhando cada vez mais notoriedade ${ }^{39}$, especialmente entre casais de alto nível de escolaridade e residentes em áreas urbanas.

Considerando que os indicadores calculados de cobertura vacinal por meio de informações administrativas podem superestimar essa cobertura, a inclusão de informações sobre imunização em pesquisas domiciliares pode ser um instrumento promissor para o monitoramento contínuo das metas de vacinação, assim como para a identificação de heterogeneidade de cobertura entre grupos populacionais.

Embora a coleta de informações dos cartões de vacina das crianças seja o processo mais custoso para obter informações de imunização, este estudo indica que essa forma seria a mais adequada de se mensurar a cobertura vacinal no contexto brasileiro em comparação às informações declaradas pelas mães. Garantir que a cobertura vacinal continue universal e que doenças infecciosas até então erradicadas no Brasil não ressurjam é um desafio em termos de saúde pública e deve ser encarada como uma das prioridades da Atenção Primária à Saúde no país. 


\section{REFERÊNCIAS}

1. Victora C, Aquino E, Leal MC, Monteiro C, Barros F, Szwarcwald C. Maternal and child health in Brazil: progress and challenges. Lancet. 2011;377(9780):1863-76. http://dx.doi.org/10.1016/S0140-6736(11)60138-4.

2. Paim J, Travassos C, Almeida C, Bahia L, Macinko J. The Brazilian health system: history, advances, and challenges. Lancet. 2011;377(9779):1778-97. http://dx.doi.org/10.1016/S0140-6736(11)60054-8. PMid:21561655.

3. Brasil. Ministério da Saúde, Secretaria de Vigilância em Saúde. Programa Nacional de Imunizações: 30 anos. Série C. Brasília: Ministério da Saúde; 2003.

4. Brasil. Ministério da Saúde. SVS-PNI. Departamento de Informática do SUS - DATASUS [Internet]. 2016 [citado em 2016 Out 1]. Disponível em: http://datasus.saude.gov.br.

5. Teixeira AMDS, Mota ELA. Denominadores para o cálculo de coberturas vacinais: um estudo das bases de dados para estimar a população menor de um ano de idade. Epidemiol Serv Saude. 2010;19(3):187-203. http://dx.doi.org/10.5123/S1679-49742010000300002.

6. Moraes J, Ribeiro M, Simões O, Castro P, Barata R. Qual é a cobertura vacinal real?. Epidemiol Serv Saude. 2003;12(3):147-53.

7. Moraes J, Ribeiro M. Desigualdades sociais e cobertura vacinal. Rev Bras Epidemiol. 2008;11(Supl 1):11324.

8. Pedraza D. Qualidade do Sistema de Informações sobre Nascidos Vivos. Ciênc Saúde Colet. 2012;17(10):2729-37.

9. Miranda A, Scheibel I, Tavares M, Takeda S. Avaliação da cobertura vacinal do esquema básico para o primeiro ano de vida. Rev Saúde Pública. 1995;29(3):208-14. http://dx.doi.org/10.1590/S003489101995000300008.

10. Brasil. Ministério da Saúde, Departamento de Ciência e Tecnologia. PNDS 2006 - Pesquisa Nacional de Demografia e Saúde da Criança e da Mulher. Relatório Técnico. Brasília: Ministério da Saúde; 2008.

11. Yokokura, AVCP, Silva, AAMD, Bernardes, ACF, Lamy, F Fo, Alves, MTSSDB, Cabra, NAL, et al. Cobertura vacinal e fatores associados ao esquema vacinal básico incompleto aos 12 meses de idade, São Luís, Maranhão, Brasil, 2006. Cad Saúde Pública. 2013;29(3):522-34.

12. Barata R, Ribeiro $M$, Moraes J, Flannery B. Socioeconomic inequalities and vaccination coverage: results of an immunisation coverage survey in 27 Brazilian capitals, 2007-2008. J Epidemiol Community Health. 2012;66:934-41.

13. Brasil. Pesquisa Nacional de Saúde 2013: Percepção do estado de saúde, estilos de vida e doenças crônicas. Rio de Janeiro: IBGE; 2014.

14. Bayas JM, Izquierdo C, Ruiz L, Sintes X, Sousa D, Celorrio JM, et al. Validity of self-reported pneumococcal vaccination status in the elderly in Spain. Vaccine. 2009;27(34):4560-4. http://dx.doi.org/10.1016/j. vaccine.2009.05.057. PMid:19508910.

15. Irving SA, Donahue JG, Shay DK, Ellis-Coyle TL, Belongia EA. Evaluation of self-reported and registry-based influenza vaccination status in a Wisconsin cohort. Vaccine. 2009;27(47):6546-9. http://dx.doi.org/10.1016/j. vaccine.2009.08.050. PMid:19729083.

16. Brown C, Clayton-Boswell H, Chaves SS, Prill MM, Iwane MK, Szilagyi PG, et al. Validity of parental report of influenza vaccination in young children seeking medical care. Vaccine. 2011;29(51):9488-92. http:// dx.doi.org/10.1016/j.vaccine.2011.10.023. PMid:22015394.

17. King JP, McLean HQ, Belongia EA. Validation of self-reported influenza vaccination in the current and prior season. Influenza Other Respir Viruses. 2018;12(6):808-13. http://dx.doi.org/10.1111/irv.12593. PMid:30028081.

18. Llupià A, García-Basteiro AL, Mena G, Ríos J, Puig J, Bayas JM, et al. Vaccination behaviour influences self-report of influenza vaccination status: a cross-sectional study among health care workers. PLoS One. 2012;7(7):e39496. http://dx.doi.org/10.1371/journal.pone.0039496. PMid:22808039.

19. Loulergue P, Pulcini C, Massin S, Bernhard M, Fonteneau L, Levy-Brühl D, et al. Validity of self-reported vaccination status among French healthcare students. Clin Microbiol Infect. 2014;20(12):01152-4. http:// dx.doi.org/10.1111/1469-0691.12759. PMid:25040583.

20. MacDonald R, Baken L, Nelson A, Nichol KL. Validation of self-report of influenza and pneumococcal vaccination status in elderly outpatients. Am J Prev Med. 1999;16(3):173-7. http://dx.doi.org/10.1016/ S0749-3797(98)00159-7. PMid:10198654. 
21. Martin LM, Leff M, Calonge N, Garrett C, Nelson DE. Validation of self-reported chronic conditions and health services in a managed care population. Am J Prev Med. 2000;18(3):215-8. http://dx.doi.org/10.1016/ S0749-3797(99)00158-0. PMid:10722987.

22. Rolnick SJ, Parker ED, Nordin JD, Hedblom BD, Wei F, Kerby T, et al. Self-report compared to electronic medical record across eight adult vaccines: do results vary by demographic factors? Vaccine. 2013;31(37):3928-35. http://dx.doi.org/10.1016/j.vaccine.2013.06.041. PMid:23806243.

23. Shenson D, DiMartino D, Bolen J, Campbell M, Lu PJ, Singleton JA. Validation of self-reported pneumococcal vaccination in behavioral risk factor surveillance surveys: experience from the sickness prevention achieved through regional collaboration (SPARC) program. Vaccine. 2005;23(8):1015-20. http://dx.doi.org/10.1016/j. vaccine.2004.07.039. PMid:15620474.

24. Skull SA, Andrews RM, Byrnes GB, Kelly HA, Nolan TM, Brown GV, et al. Validity of self-reported influenza and pneumococcal vaccination status among a cohort of hospitalized elderly inpatients. Vaccine. 2007;25(25):4775-83. http://dx.doi.org/10.1016/j.vaccine.2007.04.015. PMid:17499402.

25. Lu PJ, Dorell C, Yankey D, Santibanez TA, Singleton JA. A comparison of parent and provider reported influenza vaccination status of adolescents. Vaccine. 2012;30(22):3278-85. http://dx.doi.org/10.1016/j. vaccine.2012.03.015. PMid:22445809.

26. Boakye EA, Tobo BB, Osazuwa-Peters N, Mohammed KA, Geneus CJ, Schootman M. A comparison of parent-and provider-reported human papillomavirus vaccination of adolescents. Am J Prev Med. 2017;52(6):742-52. http://dx.doi.org/10.1016/j.amepre.2016.10.016. PMid:27890518.

27. Zimmerman RK, Raymund M, Janosky JE, Nowalk MP, Fine MJ. Sensitivity and specificity of patient selfreport of influenza and pneumococcal polysaccharide vaccinations among elderly outpatients in diverse patient care strata. Vaccine. 2003;21(13-14):1486-91. http://dx.doi.org/10.1016/S0264-410X(02)00700-4. PMid:12615445.

28. Mangtani $P$, Shah A, Roberts JA. Validation of influenza and pneumococcal vaccine status in adults based on self-report. Epidemiol Infect. 2007;135(1):139-43. http://dx.doi.org/10.1017/S0950268806006479. PMid:16740194.

29. Gordon NP, Wortley PM, Singleton JA, Lin TY, Bardenheier BH. Race/ethnicity and validity of self-reported pneumococcal vaccination. BMC Public Health. 2008;8(1):227. http://dx.doi.org/10.1186/1471-2458-8-227. PMid:18598363.

30. Andrade MV, Noronha K, Cardoso CS, Oliveira CD, Calazans JA, Souza MN. Challenges and lessons from a primary care intervention in a Brazilian municipality. Rev Saude Publica. 2019;53:45. http://dx.doi. org/10.11606/S1518-8787.2019053000457. PMid:31066823.

31. Domingues CMAS, Teixeira AMDS. Coberturas vacinais e doenças imunopreveníveis no Brasil no período 1982-2012: avanços e desafios do Programa Nacional de Imunizações. Epidemiol Serv Saude. 2013;22(1):927. http://dx.doi.org/10.5123/S1679-49742013000100002.

32. Brasil. Lei no 13.709, de 14 de agosto de 2018. Lei Geral de Proteção de Dados Pessoais (LGPD). Diário Oficial da União; Brasília; 2018.

33. Landis JR, Koch GG. The measurement of observer agreement for categorical data. Biometrics. 1977;33(1):159-74. http://dx.doi.org/10.2307/2529310. PMid:843571.

34. McHugh ML. Interrater reliability: the kappa statistic. Biochem Med. 2012;22(3):276-82. http://dx.doi. org/10.11613/BM.2012.031. PMid:23092060.

35. Associação Brasileira de Empresas de Pesquisa. Critério de classificação econômica Brasil. São Paulo: ABEP; 2008.

36. Cordeiro EL, Silva LSR, Urquiza JL, Nascimento MA, Silva RM, Souza GCS, et al. conhecimento das mães sobre o esquema vacinal de seus filhos assistidos em uma unidade básica de saúde. Brazilian Journal of Health Review. 2019;2(1):644-60.

37. Poland GA, Jacobson RM. Understanding those who do not understand: a brief review of the antivaccine movement. Vaccine. 2001;19(17-19):2440-5. http://dx.doi.org/10.1016/S0264-410X(00)00469-2. PMid:11257375.

38. Hornsey MJ, Harris EA, Fielding KS. The psychological roots of anti-vaccination attitudes: a 24-nation investigation. Health Psychol. 2018;37(4):307-15. http://dx.doi.org/10.1037/hea0000586. PMid:29389158.

39. Barbieri CLA, Couto MT. Decision-making on childhood vaccination by highly educated parents. Rev Saude Publica. 2015;49:18. http://dx.doi.org/10.1590/S0034-8910.2015049005149. PMid:25830870. 